\title{
Evidence-Based Mental Health: the first year
}

This is the first issue of the second volume of Evidence-Based Mental Health (EBMH). The continued existence of the journal shows the number of high quality studies in the field of mental health. The contents of the journal also highlight the fact that high quality research is done across a wide range of disorders and in a wide range of populations. We believe that this is particularly important in the area of mental health, where it is often believed that an evidence base is missing. We applaud the efforts of researchers worldwide who often struggle to obtain funding for research into these disabling disorders and to get those findings published. The global burden of mental disorders is now increasingly acknowledged, ${ }^{1}$ and we hope that a commensurate increase in funding is made available to allow improvements in both the quantity and quality of mental health research.

\section{Production of EBMH}

The basic production process of $E B M H$ is similar to that for Evidence-Based Medicine and involves a comparable number of steps and individuals. ${ }^{2}$ We would like to thank the editorial staff at McMaster University (research associates Cindy Walker-Dilks, and Angela Eady; production supervisor Dawn Jedraszewski; and editorial assistants Laurie Gunderman, Bharati Purohit, and Nancy Bordignon) and at the BMJ Publishing Group (technical editor Susan King and marketing executive Ruth Straube). Thanks also to the clinicians who have provided commentaries over the past year, their input has been invaluable and this journal would not be possible without them. We currently have 230 commentators from 22 countries registered on our database. By discipline, there are 145 psychiatrists, 54 psychologists, 11 nurses, and 20 from other areas such as general practice, paediatrics, and general internal medicine. We would like to encourage interested clinicians from all mental health disciplines and from all over the world to register as commentators with the journal. We are particularly keen to recruit commentators in some of the specialist areas of clinical activity such as substance use. If you are interested in being a commentator please fill out the call for commentators form inserted in this or previous issues, or fill in the commentator form found on the web at http://www.evidbasedmentalhealth.com.

Finally, we would like to thank Brian Haynes for his expert advice and encouragement during the first year of the journal and the Royal College of Psychiatrists for its enthusiastic support of the journal.

\section{Journals}

For the sake of efficiency, we must monitor the journals we continually review to determine if any of the original studies or systematic reviews pass our criteria for inclusion in $E B M H$ (these criteria are found in the purpose and procedure section, p 2-3). We monitor the journals so that we can eliminate those that contribute no articles. Our policy is as follows: any journal can be nominated for review at any time. If we can obtain copies of the journal, staff at McMaster University will review con-
Journals contributing to Evidence-Based Mental Health in 1998

\begin{tabular}{|c|c|c|c|}
\hline Journal & $\begin{array}{l}\text { Number of } \\
\text { articles } \\
\text { abstracted }\end{array}$ & $\begin{array}{l}\text { Number of articles } \\
\text { cited in "other } \\
\text { articles noted" }\end{array}$ & Total \\
\hline Acta Psychiatr Scand & 1 & 2 & 3 \\
\hline Am J Psychiatry & 9 & 6 & 15 \\
\hline Am J Public Health & 2 & - & 2 \\
\hline Ann Intern Med & - & 1 & 1 \\
\hline Arch Gen Psychiatry & 11 & 5 & 16 \\
\hline Arch Intern Med & 1 & 4 & 5 \\
\hline Behav Res Ther & 1 & 2 & 3 \\
\hline$B M J$ & 2 & 4 & 6 \\
\hline BrJ Gen Pract & 1 & - & 1 \\
\hline Br J Psychiatry & 7 & 3 & 10 \\
\hline \multicolumn{4}{|l|}{ Canadian Coordinating Office for } \\
\hline Health Technology Assessment & 3 & - & 3 \\
\hline \multicolumn{4}{|l|}{ Clinical Psychology: Science and } \\
\hline Practice & - & 1 & 1 \\
\hline CMAI & 1 & - & 1 \\
\hline Cochrane Library & 9 & 7 & 16 \\
\hline Cognitive Therapy and Research & 1 & - & 1 \\
\hline Diabetes Care & 1 & - & 1 \\
\hline Int J Geriatr Psychiatry & 1 & - & 1 \\
\hline$J A M A$ & 9 & 4 & 13 \\
\hline J Abnorm Psychol & 1 & - & 1 \\
\hline JAdv Nurs & - & 2 & 2 \\
\hline Affect Disord & 1 & 1 & 2 \\
\hline JAm Acad Child Adolesc Psychiatry & 8 & 2 & 10 \\
\hline Am Geriatr Soc & 1 & - & 1 \\
\hline Child Psychol Psychiatry & 2 & - & 2 \\
\hline J Clin Exp Neuropsychol & - & 1 & $\overline{1}$ \\
\hline Clin Psychiatry & - & 1 & 1 \\
\hline J Clin Psychopharmacol & 2 & 3 & 5 \\
\hline Consult Clin Psychol & 6 & 2 & 8 \\
\hline Journal of Counseling Psychology & 1 & - & 1 \\
\hline Lancet & 1 & - & 1 \\
\hline N Engl J Med & 3 & 1 & 4 \\
\hline Neurology & 3 & 1 & 4 \\
\hline Pediatrics & 1 & - & 1 \\
\hline Psychol Bull & 2 & - & 2 \\
\hline Psychol Med & 2 & 1 & 3 \\
\hline Psychosom Med & 1 & - & 1 \\
\hline Quality in Health Care & - & 1 & 1 \\
\hline Schizophr Bull & 1 & - & 1 \\
\hline Stroke & - & 1 & 1 \\
\hline
\end{tabular}

secutive issues for 1 calendar year or until at least 100 original and review articles have been published to determine if any of these meet our criteria for scientific merit and have direct relevance for clinical practice in mental health. If 1 or more articles meet our criteria, this journal becomes part of our regular review process. If a journal contributes no articles to $E B M H$, abstracted or cited in the "other articles noted" section of the journal, we remove it from the list of reviewed journals. We have now been reviewing journals for 18 months (we started 6 months before the first issue) and so, for volume 2 and after this issue, we will stop reviewing several journals.

The table shows which journals provided articles for the first volume. In total we reviewed 46 journals. Relatively few sources yielded 10 or more articles that were either abstracted or cited in the "other articles noted" section. These included the leading journals American Journal of Psychiatry, Archives of General Psychiatry, British Journal of Psychiatry, the Cochrane Library,JAMA, and Journal of the American Academy of Child and Adolescent Psychiatry. Although these 6 sources yielded over $50 \%$ of our abstracts, we abstracted articles and cited articles from 39 journals in total-many that are not 
primarily mental health journals. It is noticeable that a North American general medical journal published more mental health articles that pass our criteria than their UK counterparts.

We believe that the fact that important articles were identified in 39 journals shows the need for a journal like $E B M H$. Few clinicians would be able to regularly read that number of journals. These journals publish over 5500 original and review articles each year. This means that clinicians would have to read approximately 15 articles every day to keep up to date. Of these articles, approximately $3 \%$ pass our criteria.

\section{Articles}

In our first year we have abstracted 96 research articles. As would be expected (from the availability of funding among other things), the level of research activity is not equally distributed across clinical areas. Thus, within treatment research, for example, some interventions (such as interpersonal and psychodynamic psychotherapies) and some populations (such as people with learning disabilities) are relatively underrepresented. Other therapies (such as cognitive behaviour therapy) and other populations (such as adults with mental health problems) are well represented.

\section{Expanding the range of articles}

As we stated in the first issue of the journal, we are keen to increase the sorts of clinical questions that are answered by $E B M H$. We published an editorial by Michael Boyle that described the key methodological points to consider in the critical appraisal of prevalence studies, ${ }^{3}$ and we intend to begin to screen primary research studies from the beginning of 1999. We also intend to include qualitative studies in future issues.

\section{Advertisements}

The BMJ Publishing Group have agreed to keep the main part of the journal free from advertisements. Advertisements from pharmaceutical companies appear on the back of the journal. We hope that readers will understand the importance of the revenue from advertising for maintaining the financial viability of the journal-especially at this early stage in the development of the journal while we are building up our subscribers.

\section{$E B M H$ on the Web}

Thanks to the efforts of Andre Tomlin at the Centre for Evidence-Based Mental Health in Oxford, EBMH now has a comprehensive presence on the world wide web (url: www.psychiatry.ox.ac.uk/cebmh/). The website contains a full listing of the abstracts that have appeared in the journal, abbreviated versions of all abstracts with the full abstract and commentary of selected abstracts, and the full text of all the EBMH notebooks and editorials. One of the advantages of using the world wide web is that we can link the abstract to the full text of the journal when this is available online, as is increasingly the case. Similarly, the online purpose and procedure is linked to the primary journals. Because we have limited space in the journal, no room exists for readers to comment on or to debate the content of abstracts. We have addressed this by introducing a feedback facility on the website. We also plan to introduce a search facility to the database of abstracts

\section{EBMH on Ovid}

From January 1999, $E B M H$ has been included in the evidence-based reviews section of Ovid-a database that is increasingly available in academic libraries.

It has been an exciting year, full of surprises, a few disappointments, but always interesting. We feel privileged to be part of the evidence-based approach to mental health which can only lead to improvements in patient care and better communication between clinicians about what "works." We all hope that you, the readers of the journal, will join us either as commentators or via your feedback to making this enterprise even more worthwhile and successful.

JOHN GEDDES, MD SHIRLEY REYNOLDS, MSC DAVID STREINER, PhD PETER SZATMARI, MD Editors, Evidence-Based Mental Health NANCY WILCZYNSKI, MSc Research Associate, Evidence-Based Mental Health

1 Murray CJ, Lopez AD. Global mortality, disability, and the contribution of risk factors: global burden of disease study. Lancet 1997;349:1436-42. 2 Sackett DL, Haynes RB. 13 steps, 100 people, and 1000000 thanks [EBM notebook]. Evidence-Based Medicine 1997 Jul-Aug;2:101.

3 Boyle M. Guidelines for evaluating prevalence studies [EBMH notebook]. Evidence-Based Mental Health 1998 May;1:37-9.

\section{How to cite Evidence-Based Mental Health}

CITATION OF MATERIAL FROM THE NOTEBOOK:

- Streiner D, Geddes J. Some useful concepts and terms used in articles about diagnosis [EBMH notebook]. Evidence-Based Mental Health 1998 Feb;1:6-7.

CITATION FOR MATERIAL TAKEN FROM A STRUCTURED ABSTRACT, WRITTEN WITHOUT ATTRIBUTION BY A STAFF MEMBER:

- Caregiver training delayed admission of patients with dementia to nursing homes [abstract]. Evidence-Based Mental Health 1998 Feb;1:9. Abstract of: Brodaty H, Gresham M, Luscombe G. The Prince Henry Hospital dementia caregivers' training programme. Int J Geriatr Psychiatry 1997 Feb;12:183-92.

CITATION FOR MATERIAL TAKEN FROM A COMMENTARY TO AN ARTICLE:

- Bradley C. Commentary on "Purchase of a handgun was associated with an increased risk of suicide or death by homicide." Evidence-Based Mental Health 1998 Feb;1:28. Comment on: Cummings P, Koepsell TD, Grossman DC, et al. The association between the purchase of a handgun and homicide or suicide. Am J Public Health 1997 Jun;87:974-8. 